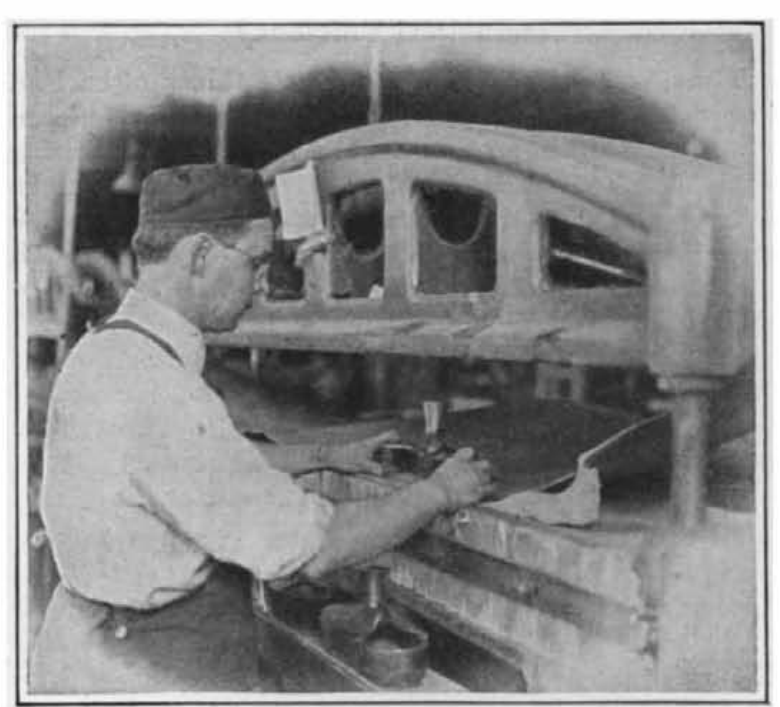

Cutting soles from beef hides

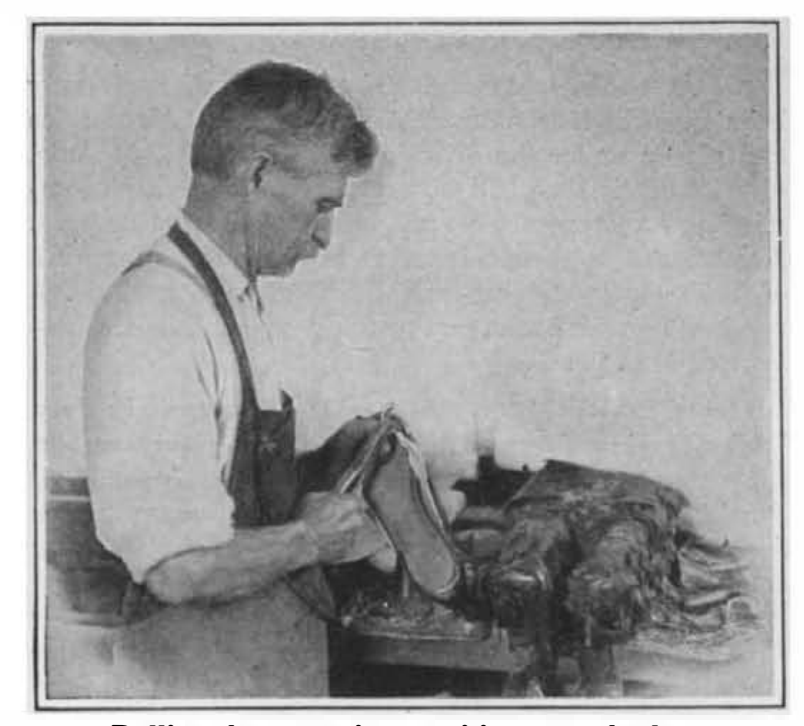

Pulling the upper into position over the last

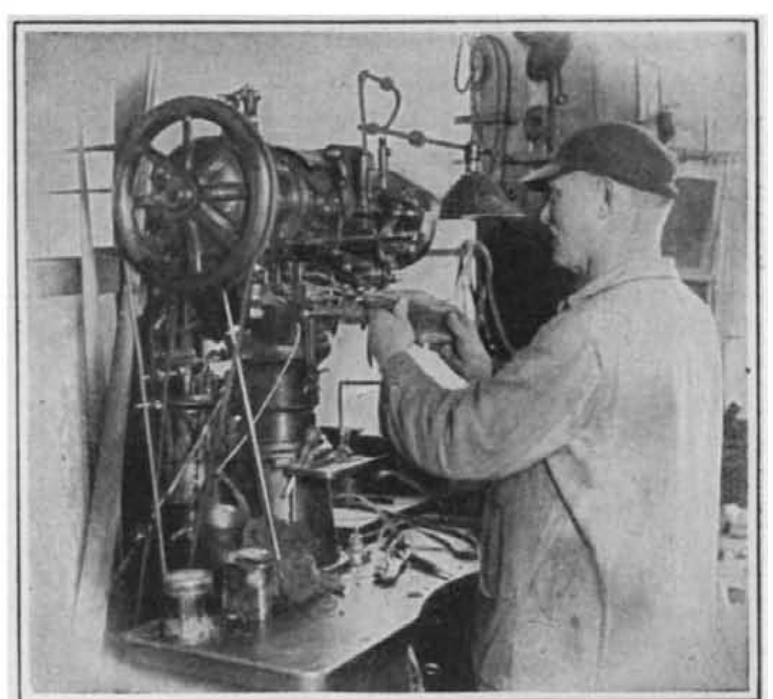

Sewing the welt to the upper and insole

\title{
Shoes for Soldiers
}

\section{Revising the Professional Fighter's Footwear to Make It Fit the Citizen's Army \\ By Arthur L. Dahl}

SOLDIERS burning with the spirit of patriotism can fight in their bare feet, as was demonstrated at Valley Forge; but under normal conditions it is just as essential to have our fighters well shod as to have them well armed. When a man's feet hurt it is not so easy to keep up enthusiasm, and Uncle Sam is doing his utmost to see that all the boys who train for service abroad are well shod. This is not as easy as would seem, for some very interesting facts were disclosed by a recent series of tests made at a number of military camps in this country. During these tests, which were under the direction of Mr. Elmer Jared Bliss, a practical shoe man of Boston, more than 42,000 men were measured for shoes, and a scientific plan was worked out for fitting men with the size and kind of shoe each should have. A new schedule of sizes has also been arranged to approximate more closely the conditions found to exist in the different training camps.

When the mobilization of our fighting forces started, and hundreds of thousands of men of all sizes and weights were sent to the various training camps, the system under which they were supplied with shoes was based upon the schedule of sizes on which shoes had been ordered for the small professional army previously maintained by the United States. This called for a certain number of pairs of shoes of a certain size, ranging, in a unit of 10,000 pairs, from a few pairs of the smallest and largest sizes, up to 1,594 pairs of size 8 .

This schedule worked very well for the small regular army, but it did not meet the requirements of the enlarged army. At the request of the Government, Mr. Bliss organized-9, corps of expert shoe men and investigations were made at military camps at $\mathrm{El} \mathrm{Paso}$ Tex., South Framingham, Mass., Quantico, Va., and Ayer, Mass., and a total of 42,000 men measured and fitted for shoes. As a result of these investigations it was found that out of 32,395 men examined by $\mathrm{Mr}$. Bliss' staff, 27,981 were wearing shoes varying from one-half to three and one-half sizes too short. Thus 80 per cent of the soldiers were improperiy shod. Thi result was not due to any fault on the part of the men in charge of the Supply Depots, but was brought about by five principal causes reported by the investigators: Lack of experience on the part of the men who really issue the Army shoes, ignorance and vanity of the men who wear the shoes, discrepancies between the sizes marked and the actual measurements of the shoes, lack

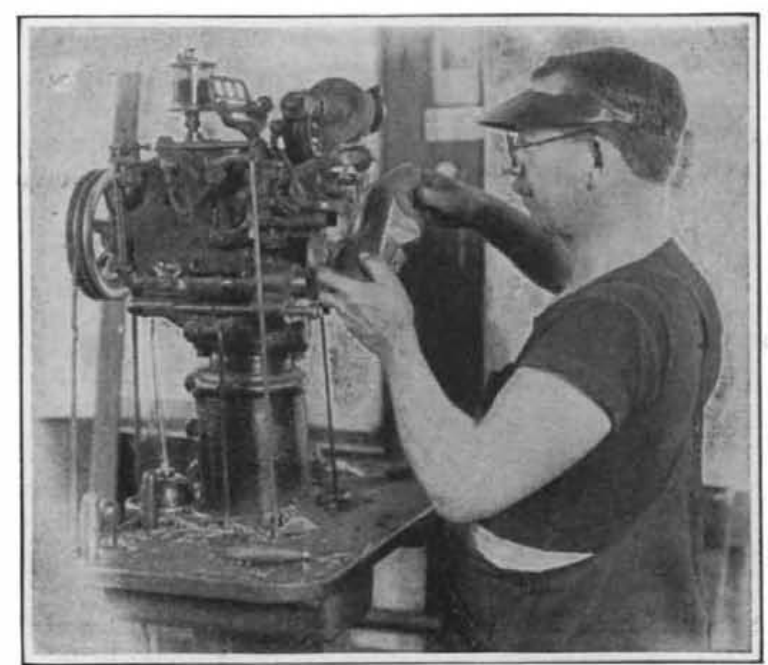

First shaping cut around the edge of the sole of proper sizes due to radical errors in present method of ordering and distributing sizes and widths, and the fact that many men who were ignorant of army standards of oversize shoes or who disliked these standards were fitted on their own estimate of the size worn in civil life.

It was found that almost universally the men asked for and insisted upon wearing shoes that under army conditions were not large enough; and the investigators decided it was absolutely necessary to devise a measuring

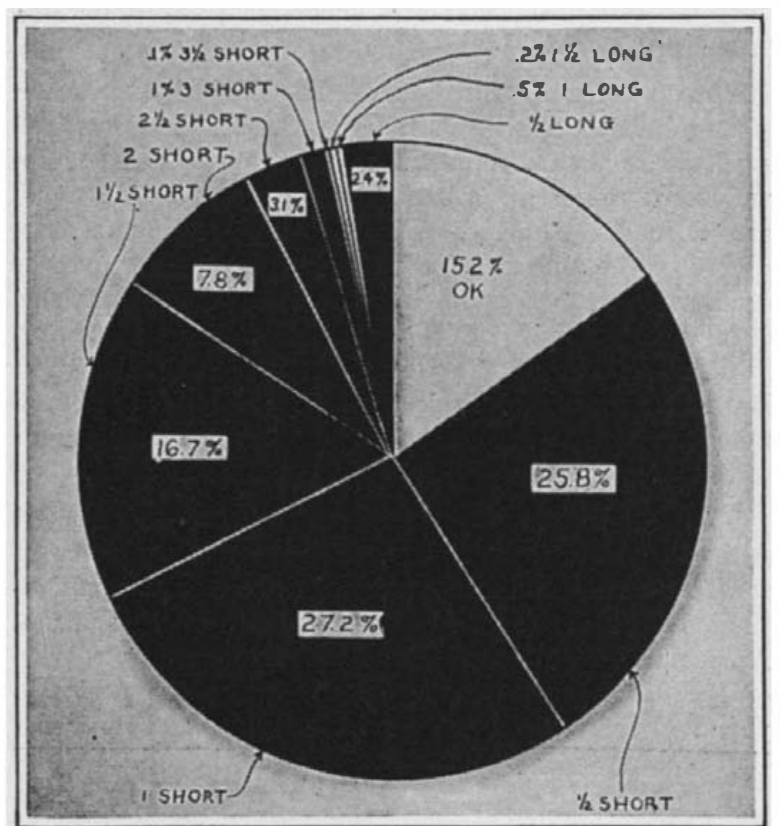

Soldiers of a typical group called for shoes from $31 / 2$ sizes short to $1 \frac{1}{2}$ sizes long, as here shown

outfit which would protect the wearer against his own ignorance and vanity and against the manufacturers' variations in sizes. This device should also be simple enough to be understood and easily operated by inexperienced shoe-fitters, and enable them to make a quick, positive and correct decision which would satisfy the wearer. After much thought and many experiments, a device was perfected which will accurately and quickly decide the size of shoe each man should wear, and it is intended to supply each distributing station with one

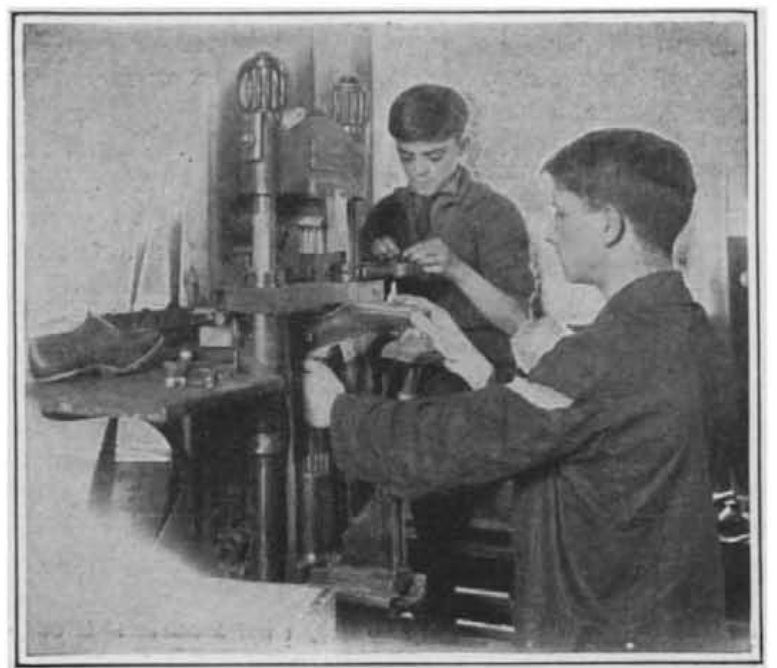

Putting on the heels after the soles are shaped of these outfits to facilitate the work of each shoe clerk. The Bliss Committee also worked out a new schedule of Army shoes, based on the demands of the thousands of men actually fitted, and this new schedule calls for a greater number of shoes of each size so that a larger variety of sizes will be available from which to fit the men. It is also proposed to put practical shoe men in charge of each shoe depot to see that the soldiers get the kind of shoes they should have rather than the kind of shoes they would choose for themselves.

During the first year of the war the government has purchased in the United States approximately 20,000,000 pairs of Army shoes, at an average price of $\$ 5$ per pair, or a total expenditure of one hundred million dollars.

The first Army shoes contracted for after we entered the war had uppers made from a chrome retanned hide which, while perfectly satisfactory for service in this country, proved to be unequal to the conditions of trench warfare in France. Consequently, the new trench shoes are being made with a much heavier upper cut from the best bark-tan natural-color cowhide or kip. These hides are from a fully matured animal and are consequently of the strongest possible fiber. They are commonly known as "packer hides" and the bulk of the supply comes from the animals slaughtered in the big packing houses.

The material used in Army shoes is of several kinds, varying according to the service to which the shoes are to be put. So far four main classifications of Army shoes have been made, known as russet, marching, field, and trench shoes. The first three are welt shoes, and the latter, a recent design based on the experience of our army in France, is a combination welt and standard screw shoe of very heavy construction. The upperleather used in the four types is as follows: russet and marching shoe, colored-boarded full-grain side or veal skin; field shoe, chrome retanned side leather; trench shoe, bark-tanned and heavily stuffed with grease, of heavy-weight bended stock. On account of the heavier construction, the new trench shoe costs about $\$ 6.25$ a pair, as against $\$ 5$ for the other types.

In contracting for Army shoes it has been the policy of the government to ask the various manufacturers of shoes to submit bids on the given specifications, naming the number of pairs which they can furnish up to a given delivery date specified by the government. In general, the contracts have been awarded, first to the lowest

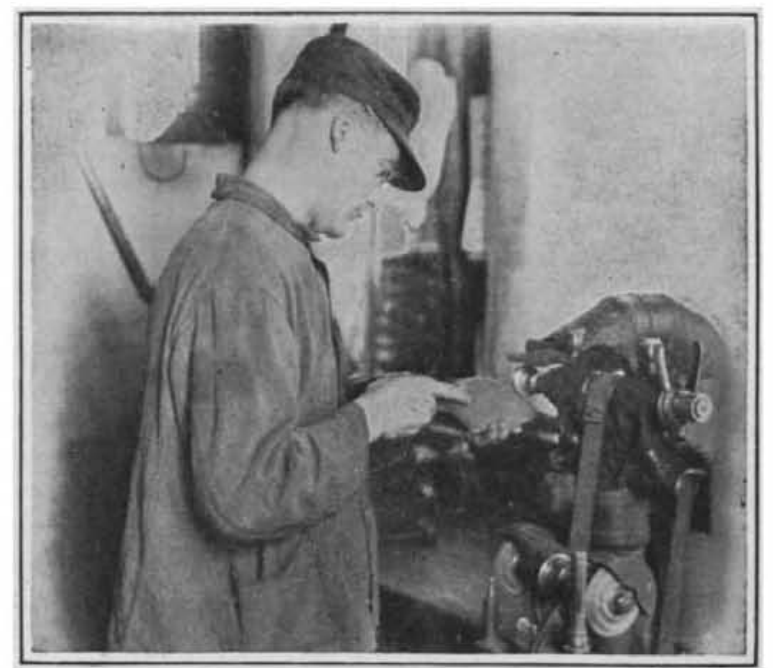

The final trim on the edge of the shoe-bottom 
bidder up to the full amount of his bid; the next lowest bidder is then given a contract for the number of shoes he can furnish, and so on until the entire quantity has been contracted for. In some case supplemental bids are called for to make up an additional quantity at the average price of the awards made on the first contract have not profits for the successful bidders on any of the army shoes so far.

The Army specifications provide that the vamp of the new shoe must be not less than $2 \frac{1}{2}$ millimeters in thickness and not more than 3 millimeters. The quarter or top has a minimum of $1 \frac{9}{10}$ millimeters and a maximum of $21 / 2$. In order to live up to these specifications, all the upper material, after being cut, has to be sorted and tested by a gage to come within the government requirements.

Furthermore, the leather is again sorted at the factory, the heavier weight hides being cut into large shoes and the lighter weight hides into smaller shoes.

The outer soles and middle soles used on Army shoes are cut from fine-haired or green salted hides of the best quality tanned with vegetable materials such as oak or hemlock bark. The thickness of these soles is rigidly specified and must be between nine and eleven iron. Any soles as much as half an iron under weight are rejected although a half iron is only $9^{\frac{1}{3}}$ of an inch. This sole leather is not only measured for thickness but is analyzed to see that it does not contain an excessive amount of weighting material, such as glucose or epsom salts.

The inner soles are extremely heavy, ranging from $61 / 2$ to $71 / 2$ iron, which is about the same weight as that used for women's outersoles. The same care is taken in selecting stock for this purpose as for the outer soles. Heels and tops lifts are of solid leather. No shoddy or imitation leather is accepted. The government main tains an inspection service in all factories where Army tains an inspection service in all factories where Army
shoes are being made. These. inspectors look over the quality of the sole leather and heels, upper leather and the finished shoes. Each shoe is stamped with the inspector's name before being shipped from the factory.

The manufacture of shoes is one of the most intricate and complicated processes found in any industry. In making an ordinary shoe there are 174 machine opera tions performed upon 154 different machines, and 36 hand operations, or a total of 210 processes. The principal methods of manufacturing shoes are known as the Goodyear welt; McKay; turned; standard screw; pegged; and nailed. The better class of shoes are sewed by either the Goodyear or McKay machines. The "turned" or "turn" method is used in making fine shoes and slippers for women and children. The chief difference between the turn shoe and the welt or McKay is the absence of an insole. Only good leather of pliable quality can be used in making this kind of a shoe, as it is made wrong side out and then turned right side out.

The standard screw shoe is made by tacking the heavy outsole in place and fastening it by means of screws. The metal which forms this fastening is in the form of wire with continuous screw thread. When the screw reaches the inside of the shoe, the machine automatically cuts it of and feeds to the next fastening. This method makes a strong but stiff shoe.

In making a new model of shoe, a wooden master last is first modeled from the human foot. The ordinary last is made of wood but it has a plate of iron along the (Concluded on page 554)

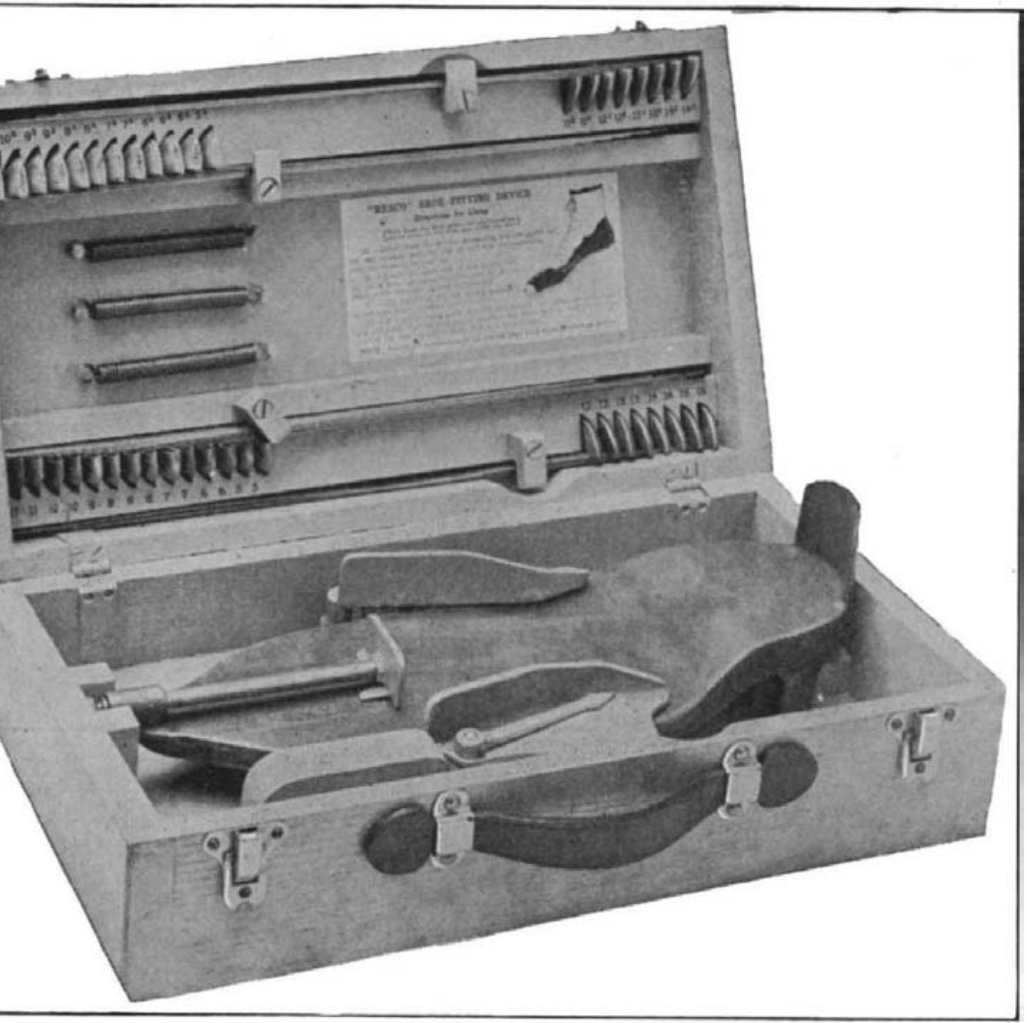

The Army shoe-fitting outfit just adopted

Surgery by Mathematical Formula By Robert G. Skerrett

Chemistry, mathematics, and the microscope ar proving potent agencies in minimizing the ravage of bullet, shell, bomb, and the other baneful instrumentalities employed by the Teutons on the European battle fronts. For the medical man has had to measure forces with the insidious workings of infinitesimal microorganisms, and these have in hundreds of thousands of

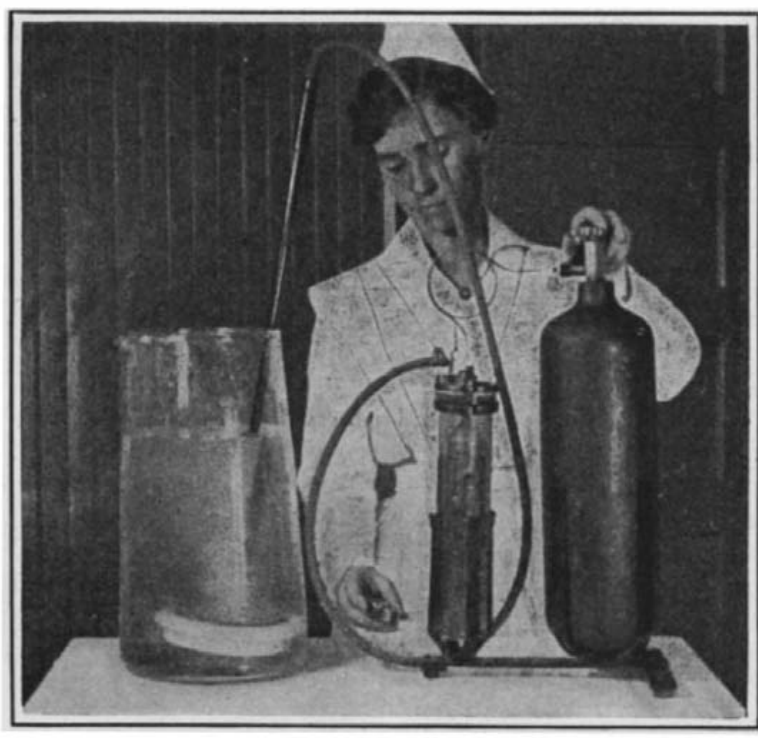

Adding liquid chlorine to a soda solution-the latest method of preparing the Dakin antiseptic solution of sodium hypochlorite

cases wrought havoc out of all proportion to the original extent of the wounds. Virulent bacteria have aggravated relatively trifling hurts, and have radically altered the problem of the military surgeon. The vast majority of the soldiers who have been wounded have been found afflicted with suppurating injuries when ultimately dealt with at the base hospitals; and this state of affairs has entailed a high percentage of ampu- tations and involved physical impairments of a more or less extensive nature. Not only that, but in the earlier period of the war suffering was dreadfully prolonged and lives sacrificed mainly because the scalpe could not deal conclusively with the microorganisms and their poisonous effects.

Nature has given us in our bodily cuticle a natural defense against the billions of germs that lie in wait for us at well-nigh every turn. Most of us little realize it, but every break in the skin is a breach through which bacteria may penetrate our physical stronghold and possibly drive us to the wall in a feverish struggle for life. Fortunately, we dwellers of the city have become immunized in large measure to many of the micro-organisms that surround us. Not so "over there," because the bacilli that lurk upon the battle ground are those of tetanus, gas-gangrene, and certain putrefactive organisms They are there in noxious abundance simply because of the character of the fertilizers that have been strewn upon those erstwhile productive acres to make them fruitful. No wonder, then, that infected wounds greatly predominate.

Accordingly, if he be stricken in the trenches or thereabouts, it is next to impossible to safeguard the soldier by precautionary measures against the inoculation of one or more types of these bacill. The best that can be done to help him is to neut micro-organisms and, accepting their presence, to destroy them before they can gain the upper hand against the natural resistance of the body and the coöperative labors of the surgeon. This is just exactly what Doctor Alexis Carrel of the Rockefeller Institute of Medical Research initiated quite three years ago just back of the Western Front in France.

Doctor Carrel recognized shortly after he joined the French ambulance service that the surgeon's task would be a hopeless one as a rule if he could not find a way to sterilize infected wounds. The problem was not that of applying the traditional ounce of prevention but of resorting to a pound of cure that could be relied upon to do the delayed work well and thoroughly. Theoretically, this scheme of treatment was directly opposed to that advocated by the conservative members of the medical profession, who for many months after the outbreak of hostilities could not bring themselves to realize that peacetime surgery and wartime surgery differed in some profound respects.

Undeterred by the criticism of his confreres, Doctor Carrel pursued his investigations; and out of the months of patient, painstaking, and exact researches carried out by him and his associates, was evolved what is generally known as the Carrel-Dakin treatment for infected wounds. The thing sought was a germicide that would be equally fatal to all micro-organisms carried into a wound and yet which would be so mild in its operation that it would not irritate the raw surfaces of the injury. This was a pretty large order, and it is not surprising that more than 200 sterilizing fluids were tested before hypochlorite of soda was chosen. The essential problem was to free it of certain irritative alkaline ingredients.

Today, the practice at the War Demonstration Hospital in New York city, established by the Rockefeller Institute, is to use chlorine produced by an electrolytic process. This insures absolutely pure liquid chlorine and enables the chemist to control the strength of the germicide to a nicety. The liquid chlorine is passed through a solution of sodium carbonate, and in this (Concluded on page 556)

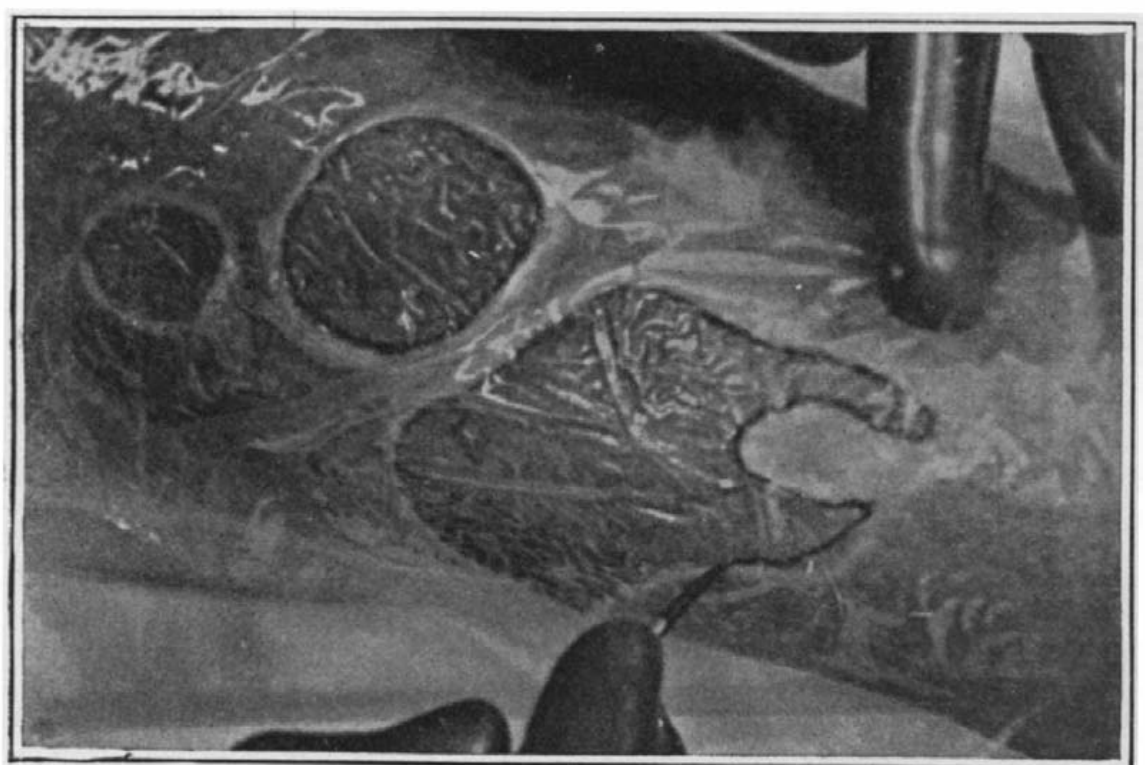

Making traces of the contour of a healing wound on a thin sheet of sterilized celluloid

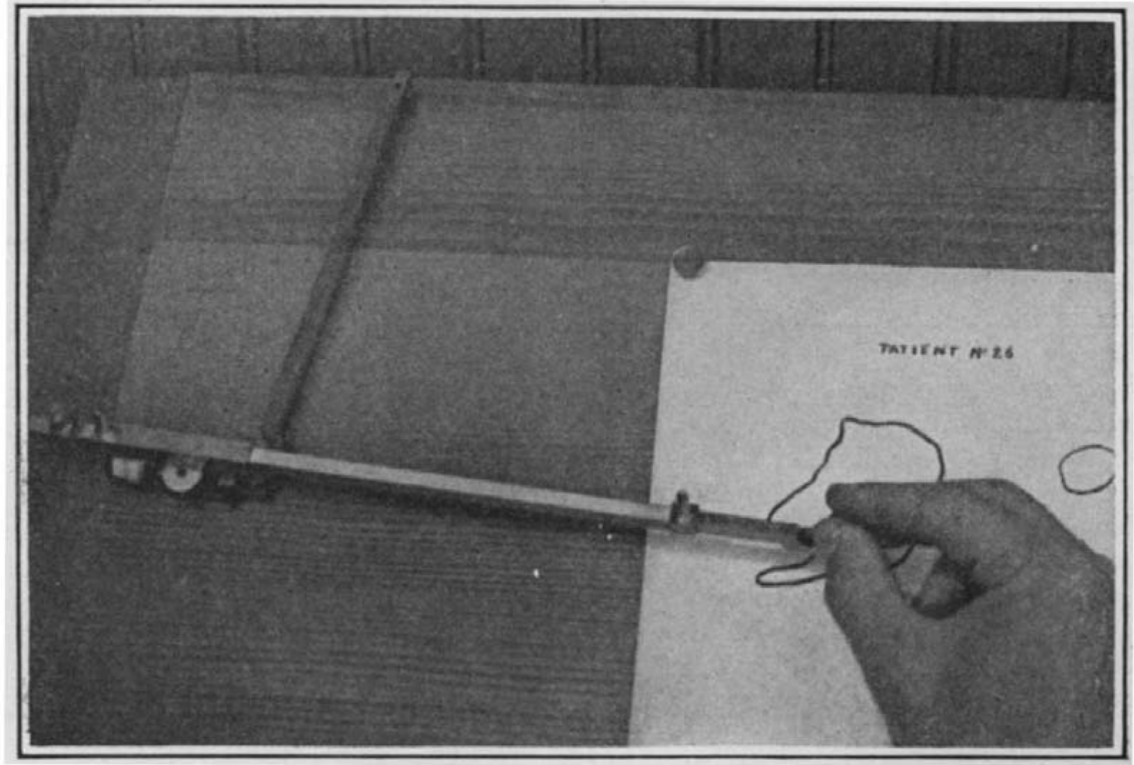

If the area of the wound, as measured on the trace by this machine, does not show the predicted daily decrease, an infected spot is sought-and found 


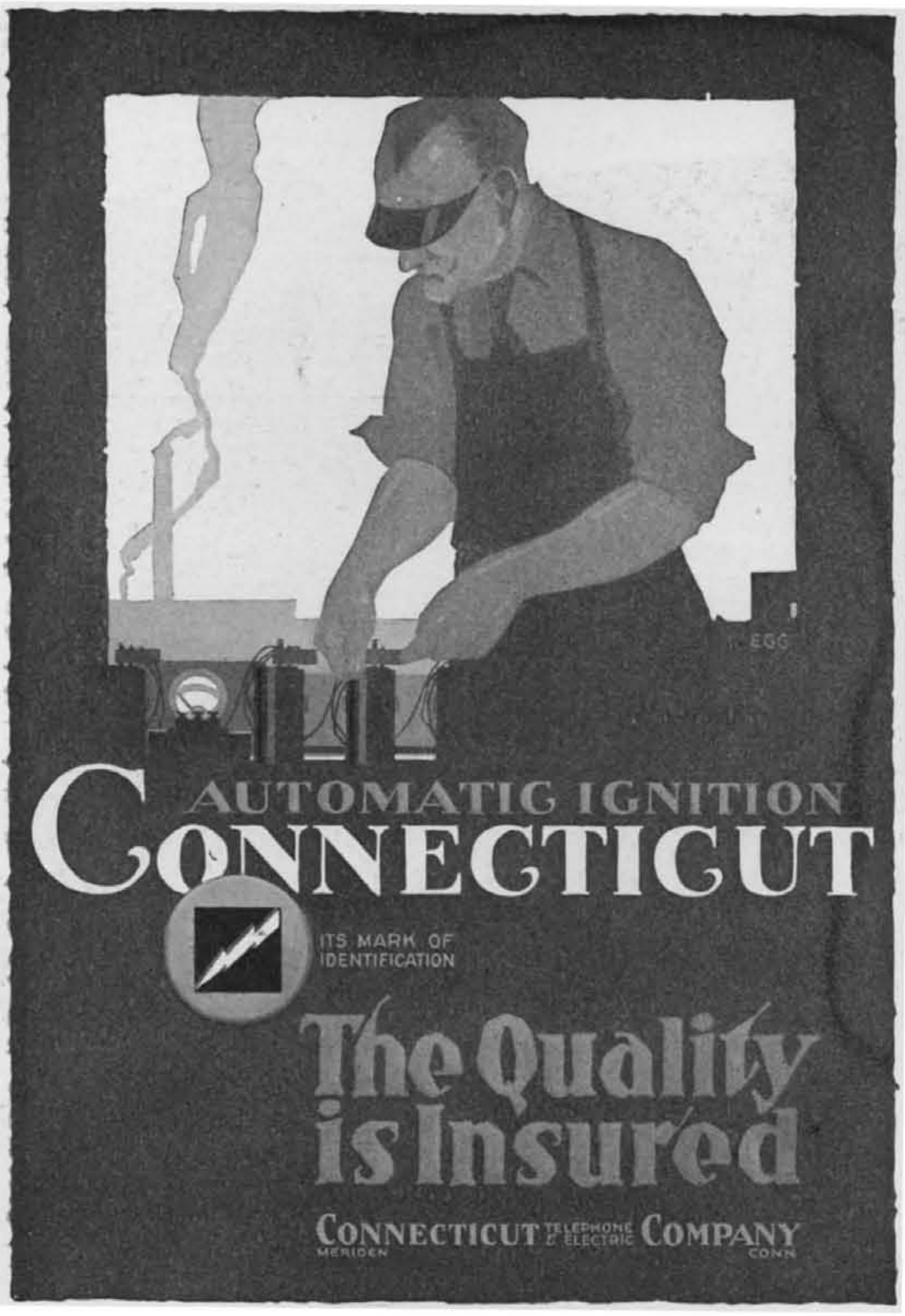

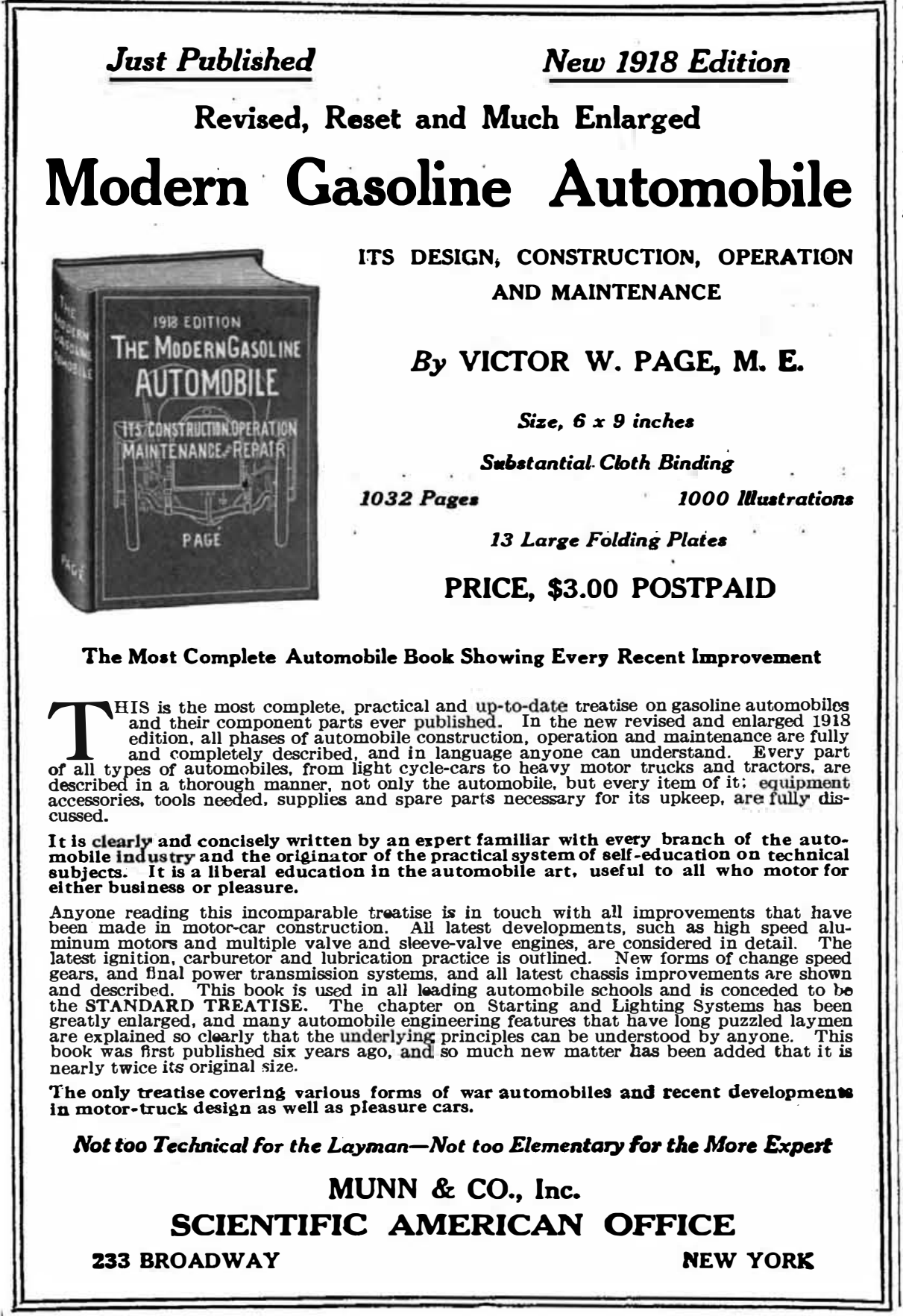

How New York City is Preparing to Meet an Air Raid

SHORTLY after we entered the great $\$$ war there appeared in the editorial columns of this journal a warning of impending air raids on our coastal cities. Using the exploits of the "U-53" and the "Deutschland," as well as the collapsible seaplanes employed on warships, by way of proving the mechanical possibility of the project, it was shown that the Germans would no doubt attempt to bombard New York city from the skies in the near future. One by one certain writers and now the authorities have accepted the possibility and probability of such raids, and at present, with the U-boats operating off our coasts, measures are being taken to safeguard our cities.

On June 4th Police Commissioner Enright of New York city issued the following statement:

"The Police Department desires to notify all residents of this city, through the press, that in the event of a raid on this city by enemy airplanes the following signals will be given:

"Siren horns or whistles will be sounded continuously for ten minutes. When this signal is given everyone should immediately open the windows of their homes or offices and go at once to the cellar of the premises After the danger has passed a signal will be given by short blasts of siren horns or whistles at intervals of one minute each for a period of 20 minutes."

On the same day, after nightfall, electric signs and all lights, except street lamps and lights in dwellings, were ordered extinguished by the police authorities. Aviators from Governor's Island flew over the city in order to determine to what extent street lamps alone might serve as guide for raiders. While the result of their for raiders. While the result of their observations is not definitely known at that street lamps and lights in dwelling will have to be darkened as in the case of London and Paris. New York city, unfortunately, is surrounded by waterways which plainly delineate the various parts of the city on a moonlight or starry night so that an airman with a map or with a slight knowledge of the metropolitan district would have little trouble finding his way to any desired part of the city.

However that may be, we are assured by the authorities that steps were taken some months ago with regard to anti-
aircraft preparations. Suitable guns have been installed not only in the city but also in a wide circle about the city. Come York undefended.

\section{Dur Wartime Barrel of Oil} (Concluded from page 5\$1)

with it as they saw fit; but with national fuel shortage at stake the control of such properties by the Government becomes at once evident.

Petroleum conservation is a subject which lends itself to treatment under three distinct subdivisions: First, the production; second, the refining; and third, the consumption.

Taking up the first phase of the subject, it is well to point out that the wastage of natural gas, while highly important, is not directly concerned with the petroleum question. It is a by-product, albeit an important if not vital one. But the mais wastage is to be found in the exploitation of the oil properties. Instances are legion in which felds have been abandoned after being only partially worked, due to poor methods of extracting the oil. Again, oil
sands have been allowed to become flooded with water, despite the fact that they contained thousands of barrels of oil through gross carelessness and indifference. Indeed, we are told by experts that in many cases only 10 per cent of the oil contained in oil sands is extracted, and that the maximum rarely reaches 70 per cent. Then there is the matter of storage, which makes for further and heavy losses because of unsatisfactory methods. As high as five per cent of the petroleum is lost through evaporation and seepage during storage and transportation. to trke the necessary precautions, and the a astage in this direction is being materially reduced. In many cases the oil is not permitted to accumulate in big lakes, there ovaporate and escape through the round before it can be shipped to the efinery. As will be noted in some of the ccompanying illustrations, oil men are ow controlling the accumulation of oil that is to say, the well is piped and the oil passed through a flow-regulating machine so that the flow can be controlled. When the oil is wanted from the well, it is permitted to pass on to the lake or reservoir and when the latter is full, the flow is hut off entirely or reduced inaterially. Obviously, this method is a vast improvement over the former one of letting the il spout out freely and accumulate in poorly enclosed basins.

When it comes to the matter of refining, ess fault can be found, although there is till vast room for improvement. The wastage in this phase of the industry is argely in the direction of insufficient application of the crude oils or by-products of refinement. However, chemists are ever at work on this problem, and it is not at all impossible that additional uses will be found for all the heavier products of refining which are now of little commercial value. If gasoline were employed solely in gasoline engines, the wastage of this valuable commodity would be materially reduced. But it is a fact that petroleum products are used for purposes where other fuels could just as well be employed. It is said that fully one-fourth of the country's oil is being used under boilers, while nother large percentage is being used in making artificial gas, despite the large coal supplies available for both those purposes. Still another source of steady and serious drainage on our petroleum resources is the export quota-20 per cent of the total production, which is sent abroad. While not wastage in the strict ense of the word, it nevertheless represents a heavy outgo of an essential and limited commodity.

Our gasoline has got to be conserved, if we are to continue enjoying those vehicles and engines operating on that fuel. Fortunately, the Government, through the Fuel Administration, is beginning to control the oil industry very much the same as the coal industry. Oil Director M. L. Requa has appointed T. A. O'Donnell of Los Angeles to be his chief aide with the special task of promoting greater coperation between all

Many of the wastes so comrron in the past will no doubt soon cease to exist; and much of the drain on our oil resources may some day be curtailed with the extensive development of water power which is now going to waste. All in all, our water power, coal and petroleum are all interllied, and the development of one soon benefits the others.

\section{Shoes for Soldiers} (Concluded from page 545)

heel. After a master last has been fash ioned by hand, duplicates are quickly turned out by lathes.

The next step in shoe-making is the preparation of patterns used for cutting the various parts of the upper portion of the hoe. The position of designer in a large hoe factory is an important one, as often the volume and permanency of trade secured by his company depends upon the styles turned out. The initial set of shoe patterns is cut in sheet iron by hand, and duplicates are reproduced in metal or cardboard by the pattern machine. Every hoe requires a large number of patterns, one for each separate piece which enters into its makeup.

Leather for shoe-making is purchased from tanneries, where it is prepared either by the vegetable or by the chemical process. Where the bark of trees is used to $\tan$ leather, months are required to complete the process. Of late years mineral ubstances, such as chrome alum, have come into general use for tanning and less time is required than with tan bark. This last is known as the "chrome tanning 